\title{
Simulation and Optimization of Temperature Effect in Solar Cells CdTe with Back Connection $\mathrm{Cu}_{2} \mathrm{O}$
}

\author{
Parinaz Khaledi $\mathbb{D D}^{1}{ }^{1}$ Mahdi Behboodnia, ${ }^{1}$ and Mohammad Karimi ${ }^{2}$ \\ ${ }^{1}$ Department of Physics, Urmia University of Technology, Urmia, Iran \\ ${ }^{2}$ Department of Physics, Shahid Madani University of Azerbaijan, Tabriz, Iran \\ Correspondence should be addressed to Parinaz Khaledi; parinaz.khaledi22@gmail.com
}

Received 1 November 2021; Revised 12 January 2022; Accepted 21 January 2022; Published 23 February 2022

Academic Editor: Sulaiman W. Harun

Copyright (C) 2022 Parinaz Khaledi et al. This is an open access article distributed under the Creative Commons Attribution License, which permits unrestricted use, distribution, and reproduction in any medium, provided the original work is properly cited.

\begin{abstract}
One of the least studied and most important parameters that are ignored in the simulation and construction of solar cells is temperature. The effect of temperature is complex, and the solar cell is a very temperature-sensitive device. Constructing highefficient solar cells is an essential task. In this paper, we simulated and studied the effect of temperature on the characteristics of $\mathrm{FTO} / \mathrm{SnO}_{2} / \mathrm{CdS} / \mathrm{CdTe} / \mathrm{Cu}_{2} \mathrm{O}$ solar cells using MATLAB and Maple software. For this purpose, first, the transport and Poisson equations, the continuity of the current, and the transfer of the carrier were solved by the drift-diffusion method and then they were discretized. We examined the cell temperature in the range of 200 to 400 Kelvin. The results showed that increasing temperature from 200 to 400 Kelvin open-circuit voltage decreases the short-circuit current. Furthermore, the filling factor first increases and then decreases. The efficiency of the solar cell also decreases sharply with increasing temperature. The results showed that, by decreasing the temperature of the solar cell, an efficiency of more than $32 \%$ can be achieved in cadmium telluride solar cells with $\mathrm{FTO} / \mathrm{SnO}_{2} / \mathrm{CdS} / \mathrm{CdTe} / \mathrm{Cu}_{2} \mathrm{O}$ structure.
\end{abstract}

\section{Introduction}

Urbanization and rapid growth in industrialization extensively bring significant increments in environmental pollution and global warming, which are vital issues alongside the energy crisis that oblige scientists to seek a suitable alternative energy source to rescue the Earth and the environment. Thin-film photovoltaic (PV) solar cell technology has grasped global attention among researchers due to its outstanding promises for renewable energy resources and substitution with fossil fuels to meet human energy needs [1]. Solar cells (SCs) as promising renewable energy sources are attracting the attention of researchers. A challenge in modern solar energy is the development of cost-effective devices. Achieving this goal requires a proper understanding of the basic physical processes of device performance. Several attempts have been made to understand the mechanism of the operating of solar cells. The impacts of variables such as morphology, light intensity, and light absorption on device performance and primarily on shortcircuit current characteristics have been extensively investigated by previous researchers [2]. The II-VI, I-III-VI, photovoltaic materials, such as CdTe, $\mathrm{Cu}(\mathrm{In}, \mathrm{Ga}) \mathrm{Se}_{2}$, $\mathrm{Cu}_{2} \mathrm{ZnSn}(\mathrm{S}, \mathrm{Se})_{4}$, and methylammonium lead triiodide $\left(\mathrm{MAPbI}_{3}\right)$, respectively, have direct bandgaps that enable light to be absorbed and converted into electricity in semiconductor layers that are just several micrometers thick. So far, more than 20 gigawatts of CdTe-based solar technology has been installed, with module efficiency now averaging $17-18 \%$ at cost-competitiveness with $\mathrm{Si}$ modules. CdTe can achieve high carrier density and longevity, enabling solar cells with open-circuit voltages of more than one [3]. The high absorption coefficient of cadmium telluride is more than $5 \times 10^{5} \mathrm{~cm}^{-1}$ and the direct band distance is 1.5 volts, which corresponds exactly to the solar spectrum and turns it into a complete solar cell material that can absorb most of the photons in the visible range, which have more energy than the bandgap to convert maximum sunlight into 
electricity [4]. So far, many studies have been done on the effect of different parameters on the functions of cadmium telluride solar cells, including the study of Jaker Hossain et al. [5] which presents that using the CdSe and $\mathrm{Sb}_{2} \mathrm{Se}_{3}$ Back Surface Field (BSF) layers significantly increased the efficiency of solar cells [5]. Other researchers have proposed different simulation methods to study the performance of cadmium telluride solar cells using doping concentration, layer thickness, and carrier lifetimes [6]. There is a lot of research on solar cells, especially cadmium telluride solar cells [7-10]. And to date, many studies have been done. Our goal in this article is to study one of the most important parameters in cadmium telluride solar cells, which has been less studied in previous works or not mentioned in most studies. An important parameter that we will examine in this research is temperature. The effect of temperature is complex and solar cells are a very temperature-sensitive device; therefore, the working temperature of solar cells is very important to achieve high performance of solar cells. When a solar cell operates at high temperatures, photovoltaic materials and device properties such as band gaps and absorption coefficients change. However, in most articles, the study of temperature changes is ignored and examines the solar cell only at room temperature [11-15]. Although experimental approaches in which studies are sometimes performed experimentally fail, attempts to analyze device performance through simulation models have shown particular success. The study of solar cell simulations is very useful for predicting the output performance of solar cells before the actual construction of the cell and will significantly reduce production costs and avoid excessive costs. Various tools for simulating solar cells are available, including wxAMPS, a 1D solar cell simulation program, Silvaco ATLAS software, SCAPS-1D software [16], GPVDM software, and more. So far, a lot of research has been done and published by these simulation tools [17-24]. We first did the programming in Maple software, and then we did the same again in MATLAB due to its high speed, and we checked the accuracy of programming as well as comparison of the results.

In this work, we will study the effect of temperature on open-circuit voltage, short-circuit current, charge coefficient, and efficiency in 5-layer solar cells with $\mathrm{FTO} / \mathrm{SnO}_{2} /$ $\mathrm{CdS} / \mathrm{CdTe} / \mathrm{Cu}_{2} \mathrm{O}$ structure by numerical simulation.

\section{The Governing Physical Equations of the Problem}

To begin with, the transport equations, the electron-hole equation, and the Poisson equation must be solved simultaneously. In some previous studies, a quasi-drift-diffusion model has been proposed in which only the electron and hole continuity equations were solved, without considering the Poisson equation. The cavity and Poisson equation as the extended one-dimensional drift-diffusion model can design, optimize, and describe the performance of various cell parameters [25].

The drift-diffusion equations can be obtained by solving the Boltzmann Transport equation (BTE) by solving for the moments of this equation. For steady-state and 1D geometry, the use of relaxation time approximation for the BTE results in

$$
\begin{aligned}
& \frac{d f}{d t}=\frac{\partial v}{\partial t} \frac{\partial f}{\partial v}+\frac{\partial x}{\partial t} \frac{\partial f}{\partial x}, \\
& \frac{d f}{d t}=\frac{f_{\circ}-f(x . v)}{\tau} .
\end{aligned}
$$

By equating the two relations above (1) and (2) and considering that $F=\mathrm{ma}, F=\mathrm{Eq}, a=\partial v / \partial t, v=\partial x / \partial t$, the BTE is represented as

$$
\frac{f_{\text {。 }}-f(x . v)}{\tau}=\frac{e E}{m^{*}} \frac{\partial f}{\partial v}+v \frac{\partial f}{\partial x} .
$$

The current density $J(x)$ is defined as

$J(x)=n \mathrm{e} v$

$$
J(x)=e \int v f(x . v) \mathrm{d} v .
$$

In (4), the integral represents the first torque of the distribution function. Multiplying (3) by $v$

$$
\frac{1}{\tau}\left\{f_{\circ} v-f(x . v) v\right\}=\frac{e E}{m^{*}} v \frac{\partial f}{\partial v}+v^{2} \frac{\partial f}{\partial x} .
$$

And integrating obtains

$$
\begin{aligned}
& \frac{1}{\tau}\left[\int f_{0} v \mathrm{~d} v-\int f(x . v) v \mathrm{~d} v\right] \\
& =\frac{e E}{m^{*}} \int v \frac{\partial f}{\partial v} \mathrm{~d} v+\frac{d}{d x} \int v^{2} f(x . v) \mathrm{d} v .
\end{aligned}
$$

Since the equilibrium distribution function in terms of $v$ is symmetric, the first integral from the left in (6) is zero.

$$
\begin{gathered}
\frac{1}{\tau}\left[-\int f(x . v) v \mathrm{~d} v\right]=\frac{e E}{m^{*}} \int v \frac{\partial f}{\partial v} \mathrm{~d} v+\frac{d}{d x} \int v^{2} f(x . v) \mathrm{d} v . \\
\text { Then, } \\
\frac{-J(x)}{e \tau}=\frac{e E}{m^{*}} \int v \frac{\partial f}{\partial v} \mathrm{~d} v-\frac{d}{d x} \int v^{2} f(x \cdot v) \mathrm{d} v, \\
J(x)=-e \tau \frac{e E}{m^{*}} \int v \frac{\partial f}{\partial v} \mathrm{~d} v-e \tau \frac{d}{d x} \int v^{2} f(x . v) \mathrm{d} v .
\end{gathered}
$$

Calculating the first integral in (9), by applying the fractional method,

$$
\begin{aligned}
\int u \mathrm{~d} v & =u v-\int v \mathrm{~d} u \\
\int v \frac{\partial f}{\partial v} \mathrm{~d} v & =v f(x . v)-\int f(x . v) \mathrm{d} v, \\
\int v \frac{\partial f}{\partial v} \mathrm{~d} v & =-n(x) .
\end{aligned}
$$

The second integral in (9) is equal to $v^{2} n(x)$ where $v^{2}$ represents the mean square velocity. Equating mobility $\mu$ as $\left(e \tau / m^{*}\right)$ in (9), we obtain 


$$
J(x)=-e \mu E(-(n(x)))+e \tau \frac{d}{d x} v^{2} n(x) .
$$

Thus the electric drift-diffusion current density for electrons $J(x)_{n}$ and holes $J(x)_{p}$ is obtained, respectively, as

$$
\begin{gathered}
J(x)_{n}=q n(x) \mu_{n} E(x)+q D_{n} \frac{d n}{d x}, \\
J(x)_{p}=q p(x) \mu_{p} E(x)-q D_{p} \frac{d p}{d x},
\end{gathered}
$$

where $n$ and $p$ are the densities of electrons and holes and $E(x)$ is the electric field, while $\mu_{n}$ and $\mu_{p}$ are the electron and hole mobilities and $D_{n}$ and $D_{p}$ are the electron and hole diffusivities.

For programming in MATLAB and Maple software, we have precisely discretized the governing physical equations. Generally, conservative schemes are achieved by subdivision of the computational domain into boxes surrounding the mesh points. Currents are defined on the boundaries of these elements, thus enforcing conservation. Consider the 1D electron current continuity equation under steady-state equations:

$$
\frac{1}{e} \nabla \cdot J_{n}=G
$$

which, by using half-point difference expansion based on the central difference scheme, gives

$$
\frac{1}{e}\left(\frac{J_{i+(1 / 2)}^{n}-J_{i-(1 / 2)}^{n}}{\Delta}\right)=G
$$

where $G$ is the production rate, that is, the amount of charge produced per unit of time under light illumination.

Using the electric current density for the electrons in (12) and dividing both parts by $\left(e D_{i+(1 / 2)}^{n}\right)$ give

$$
\frac{J_{i+(1 / 2)}^{n}}{e D_{i+(1 / 2)}^{n}}=\frac{e n \mu_{i+(1 / 2)}^{n} E_{i+(1 / 2)}}{e D_{i+(1 / 2)}^{n}}+\frac{d n}{d x},
$$

where $D_{n}=v_{t} \mu(x)_{n}=(k T / q) \mu(x)_{n}$.

By replacing these in (16), we acquire

$$
\frac{J_{i+(1 / 2)}^{n}}{e D_{i+(1 / 2)}^{n}}=\frac{n E_{i+(1 / 2)}}{v_{t}}+\frac{d n}{d x}
$$

Using the compound derivation rule, we have

$$
\frac{d n}{d x}=\frac{d n}{d \Psi} \frac{d \Psi}{d x}=\frac{d n}{d \Psi} \frac{\Psi_{i+1}-\Psi_{i}}{\Delta} .
$$

Substituting the above relation in (17) achieves

$$
\frac{J_{i+(1 / 2)}^{n}}{e D_{i+(1 / 2)}^{n}}=\frac{n E_{i+(1 / 2)}}{v_{t}}+\frac{d n}{d \Psi}\left(\frac{\Psi_{i+1}-\Psi_{i}}{\Delta}\right) .
$$

Dividing (19) by $\left(\left(\Psi_{i+1}-\Psi_{i}\right) / \Delta\right)$ and according to (20) and (21), we get (22):

$$
\begin{aligned}
-E & =\frac{d \Psi}{d x}=\frac{\Psi_{i+1}-\Psi_{i}}{\Delta}, \\
\frac{J_{i+(1 / 2)}^{n} \Delta}{e D_{i+(1 / 2)}^{n}\left(\Psi_{i+1}-\Psi_{i}\right)} & =\frac{n E_{i+(1 / 2)}^{n}}{v_{t}\left(-E_{i+(1 / 2)}^{n}\right)}+\frac{d n}{d \Psi}, \\
\frac{d n}{d \Psi}-\frac{n}{v_{t}} & =\frac{\Delta J_{i+(1 / 2)}^{n}}{e\left(\Psi_{i+1}-\Psi_{i}\right) D_{i+(1 / 2)}^{n}} .
\end{aligned}
$$

We calculate $J_{i-(1 / 2)}^{n}, J_{i+(1 / 2)}^{n}$ with Laplace transforms and place it in (15).

Our goal is to obtain the discrete form of the continuity equations for electrons and holes. In this work for programming, we consider Laplacian transformation equations (23) to (27):

$$
\begin{aligned}
n\left(\Psi_{i}\right) & =n_{i}, \\
n\left(\Psi_{i+1}\right) & =n_{i+1}, \\
g(\Psi) & =\frac{e^{\left(\Psi-\Psi_{i} / v_{t}\right)}-1}{e^{\left(\Psi_{i+1}-\Psi_{i} / v_{t}\right)}-1}, \\
n(\Psi) & =n_{i}[1-g(\Psi)]+n_{i+1} g(\Psi), \\
n(\Psi) & =n_{i}-n_{i} g(\Psi)+n_{i+1} g(\Psi) .
\end{aligned}
$$

Using derivatives of (25) and (27), (28)-(31) are obtained:

$$
\frac{d g(\Psi)}{d \Psi}=\frac{1}{v_{t}} \frac{e^{\left(\Psi-\Psi_{i} / v_{t}\right)}}{e^{\left(\Psi_{i+1}-\Psi_{i} / v_{t}\right)}-1}=\frac{1}{v_{t}}\left(\frac{e^{\left(\Psi-\Psi_{i} / v_{t}\right)}+1-1}{e^{\left(\Psi_{i+1}-\Psi_{i} / v_{t}\right)}-1}\right)
$$

$$
\begin{aligned}
\frac{d g(\Psi)}{d \Psi} & =\frac{1}{v_{t}}\left(\frac{e^{\left(\Psi-\Psi_{i} / v_{t}\right)}-1}{e^{\left(\Psi_{i+1}-\Psi_{i} / v_{t}\right)}-1}+\frac{1}{e^{\left(\Psi_{i+1}-\Psi_{i} / v_{t}\right)}-1}\right), \\
\frac{d g(\Psi)}{d \Psi} & =\frac{1}{v_{t}}\left(g(\Psi)+\frac{1}{e^{\left(\Psi_{i+1}-\Psi_{i} / v_{t}\right)}-1}\right), \\
\frac{d n}{d \Psi} & =-n_{i} \frac{d g(\Psi)}{d \Psi}+n_{i+1} \frac{d g(\Psi)}{d \Psi}=\left(n_{i+1}-n_{i}\right) \frac{d g(\Psi)}{d \Psi} .
\end{aligned}
$$
obtain

Then by changing the variable $x=\left(\Psi_{i+1}-\Psi_{i} / v_{t}\right)$, we

$$
\frac{d g(\Psi)}{d \Psi}=\frac{1}{v_{t}}\left(g(\Psi)+\frac{1}{e^{x}-1}\right)
$$

By changing the variable $x=\left(\Psi_{i+1}-\Psi_{i} / v_{t}\right)$ in (22), we acquire

$$
\frac{d n}{d \Psi}-\frac{n_{i}}{v_{t}}=\frac{\Delta J_{i+(1 / 2)}^{n}}{\operatorname{ex} v_{t} D_{i+(1 / 2)}^{n}}
$$


Replacing (30) by (32), we reach

$$
\left(n_{i+1}-n_{i}\right) \frac{d g(\Psi)}{d \Psi}-\frac{n}{v_{t}}=\frac{\Delta J_{i+(1 / 2)}^{n}}{\operatorname{exv}_{t} D_{i+(1 / 2)}^{n}} .
$$

And by placing (31) in (33), we will reach

$$
\left(n_{i+1}-n_{i}\right) \frac{1}{v_{t}}\left(g(\Psi)+\frac{1}{e^{x}-1}\right)-\frac{n}{v_{t}}=\frac{\Delta J_{i+(1 / 2)}^{n}}{\operatorname{exv}_{t} D_{i+(1 / 2)}^{n}} .
$$

We replace $n$ in (34) by $n(\Psi)=n_{i}-n_{i} g(\Psi)+n_{i+1} g(\Psi)$ and we come to relation

$$
\begin{aligned}
& n_{i+1} g(\Psi)-n_{i} g(\Psi)+\frac{n_{i+1}-n_{i}}{e^{x}-1}-n_{i}+n_{i} g(\Psi)-n_{i+1} g(\Psi) \\
& =\frac{\Delta J_{i+(1 / 2)}^{n}}{\operatorname{exD} D_{i+(1 / 2)}^{n}}
\end{aligned}
$$

After simplification relation (35),

$$
\frac{\left(n_{i+1}-n_{i}\right)}{e^{x}-1}-n_{i}=\frac{\Delta J_{i+(1 / 2)}^{n}}{\operatorname{exD} D_{i+(1 / 2)}^{n}} .
$$

By dividing both sides of (36) by $\left(\Delta / \operatorname{ex} D_{i+(1 / 2)}^{n}\right)$ and after factoring and simplification,

$$
J_{i+(1 / 2)}^{n}=\frac{e D_{i+(1 / 2)}^{n}}{\Delta}\left[n_{i+1} \frac{x}{e^{x}-1}-n_{i} \frac{-x}{e^{-x}-1}\right] .
$$

After simplification and using the definition of Bernoulli function $B(x)=\left(x / e^{x}-1\right)$, we reach (38), which is a discrete form of the electric current density equation for electrons.

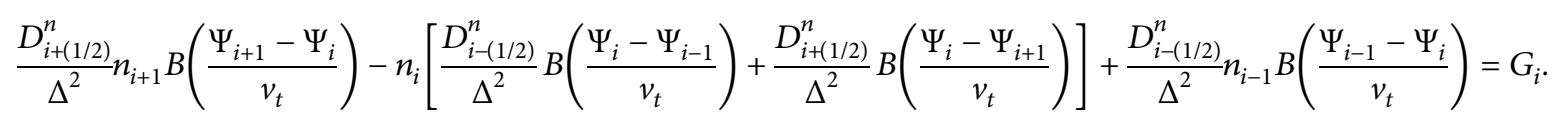

We obtained the same discrete form of the equations for the holes as

$$
\frac{D_{i+(1 / 2)}^{p}}{\Delta^{2}} p_{i+1} B\left(\frac{\Psi_{i+1}-\Psi_{i}}{v_{t}}\right)-p_{i}\left[\frac{D_{i-(1 / 2)}^{p}}{\Delta^{2}} B\left(\frac{\Psi_{i}-\Psi_{i-1}}{v_{t}}\right)+\frac{D_{i+(1 / 2)}^{p}}{\Delta^{2}} B\left(\frac{\Psi_{i}-\Psi_{i+1}}{v_{t}}\right)\right]+\frac{D_{i-(1 / 2)}^{p}}{\Delta^{2}} p_{i-1} B\left(\frac{\Psi_{i-1}-\Psi_{i}}{v_{t}}\right)=G_{i} .
$$

For software programming and simulation, we discretized other governing physical equations, such as the transport equation, the continuity equation, and the Poisson equation, just like the electric current density equations for electrons and holes, which were precisely discretized.

2.1. The Structure of the Studied Solar Cell. A group of researchers [4] studied the structure of this type of solar cell shown in Figure 1 using TCAD Silvaco-Atlas software and reported the optimal thicknesses for this type of structure using simulation. According to the reports provided in the source $[4,26]$, the optimal thicknesses for the layers FTO/ $\mathrm{SnO}_{2} / \mathrm{CdS} / \mathrm{CdTe} / \mathrm{Cu}_{2} \mathrm{O}$ were reported as $\mathrm{Cu}_{2} \mathrm{O}$ at $50 \mathrm{~nm}$, $\mathrm{CdTe}$ at $2000 \mathrm{~nm}, \mathrm{CdS}$ at $50 \mathrm{~nm}, \mathrm{SnO}_{2}$ at $100 \mathrm{~nm}$, and $\mathrm{FTO}$ at $100 \mathrm{~nm}$, respectively, with the doping concentrations of $5 \times 10^{18} \mathrm{~cm}^{-3}$ in $\mathrm{Cu}_{2} \mathrm{O}, 2 \times 10^{16} \mathrm{~cm}^{-3}$ in CdTe, $1 \times 10^{16} \mathrm{~cm}^{-3}$ in CdS, $1 \times 10^{18} \mathrm{~cm}^{-3} \mathrm{SnO}_{2}$, and $3 \times 10^{20} \mathrm{~cm}^{-3}$ in FTO [4]. They did not study the effect of temperature changes and only reported the optimal thickness and impurity at $300 \mathrm{~K}$. In our work, before investigating the effect of temperature changes, first, an $\mathrm{FTO} / \mathrm{SnO} 2 / \mathrm{CdS} / \mathrm{CdTe} / \mathrm{Cu} 2 \mathrm{O}$ solar cell was simulated as a reference structure [4] at a constant temperature of $300 \mathrm{~K}$ to ensure the accuracy and consistency of the present results with previous data. The obtained photovoltaic parameters were then compared with the simulation results, in other words, short-circuit current density (Jsc), open-circuit voltage (Voc), filling factor (FF), and conversion efficiency $(\eta)$ with the reference cell. A good match between the simulation results and the reference cell [4] indicates that the parameters and models used in the process simulation are correct.

To study the effect of temperature on various parameters in cadmium telluride solar cells, we considered a 5-layer solar cell containing $\mathrm{FTO} / \mathrm{SnO}_{2} / \mathrm{CdS} / \mathrm{CdTe} / \mathrm{Cu}_{2} \mathrm{O}$ layers. The structure of this solar cell is shown in Figure 1.

Then, after simulation, we studied temperature changes from 200 to 400 Kelvin in this structure. We reported the effect of temperature changes on open-circuit voltage, shortcircuit current, filling factor, and efficiency.

\section{Result and Discussions}

The cell efficiency as a function of p-CdTe absorber layer thickness is depicted in Figure 2. By increasing the thickness from 30 to $2000 \mathrm{~nm}$, rapid evolution is observed and then becomes stable from almost $2000-4000 \mathrm{~nm}$. With the increasing thickness, the absorption of the photons increases until the thickness reaches $2000 \mathrm{~nm}$ so that it could sufficiently absorb all the photons to get the highest efficiency of 

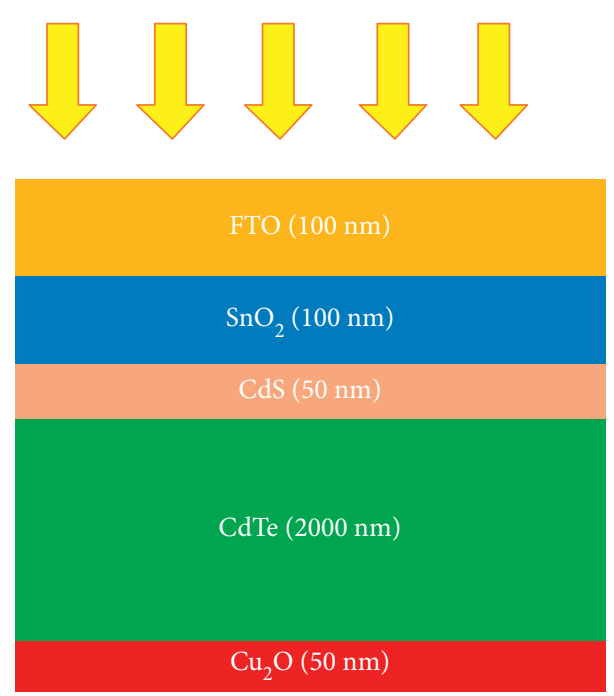

FIgURE 1: The structure of the studied solar cell.

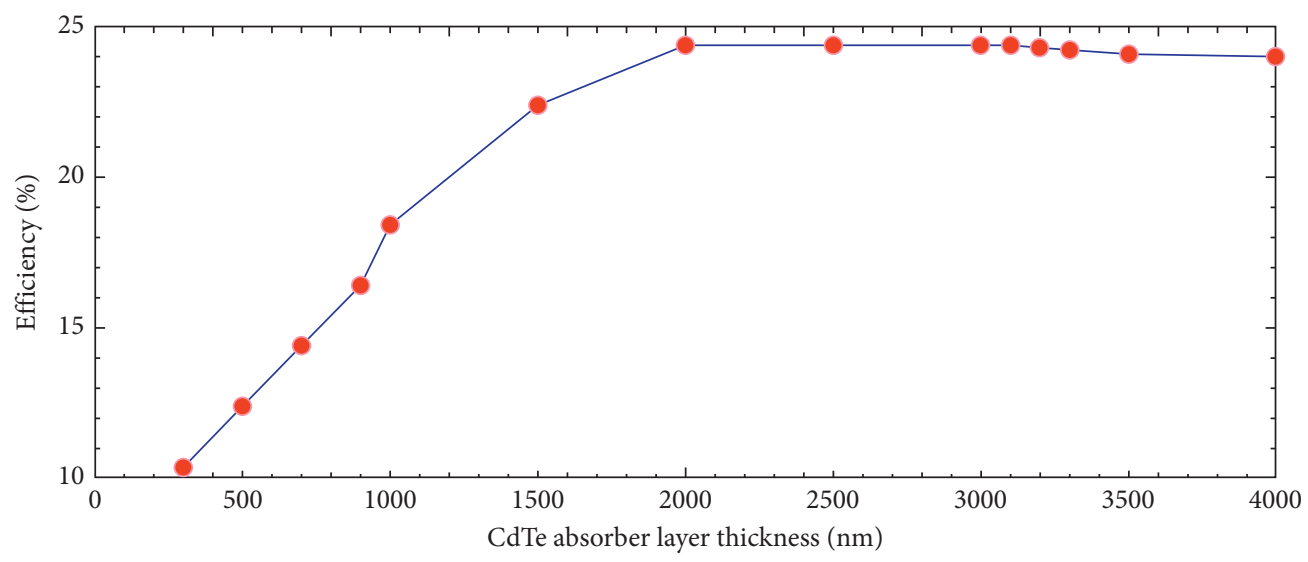

Figure 2: Efficiency versus the thickness of the CdTe adsorbent layer at a temperature of $300 \mathrm{~K}$.

$24.40 \%$. This value is in good agreement with the previously reported results $[4,26]$. Thus, $2000 \mathrm{~nm}$ is used as an optimum thickness of the CdTe absorber layer in the rest of this work.

Figure 3 shows the temperature changes from 200 to $400 \mathrm{~K}$ in terms of open-circuit voltage when the thickness of $\mathrm{CdTe}$ is $2000 \mathrm{~nm}$. In this temperature interval, the opencircuit voltage varies between 2.45 and 0.64 volts, so that when the temperature is $200 \mathrm{~K}$, the open-circuit voltage has a maximum value of 2.45 volts. At $400 \mathrm{~K}$, the open-circuit voltage drops to a minimum of 0.64 volts. In addition, at room temperature of $300 \mathrm{~K}$, the value of the open-circuit voltage is equal to 1.03 volts, which corresponds exactly to the previous work [4] and confirms our results. In addition, in $[27,28]$, the open-circuit voltage decreased with increasing temperature, which can be a reason for the accuracy of our results.

Figure 4 reveals the short-circuit surface current density changes in the temperature range $200-400 \mathrm{~K}$ at a thickness of $2000 \mathrm{~nm} \mathrm{CdTe}$. At temperature of $200 \mathrm{~K}$, the short-circuit surface current density is equal to $27.90\left(\mathrm{~mA} / \mathrm{cm}^{2}\right)$ and has the highest value. Even at room temperature, $300 \mathrm{~K}$, this value is equal to $27.59\left(\mathrm{~mA} / \mathrm{cm}^{2}\right)$, which is consistent with the results of previous work and proves the accuracy of the results. Finally, at a temperature of $400 \mathrm{~K}$, the short-circuit surface current density has the lowest value of 27.15 $\left(\mathrm{mA} / \mathrm{cm}^{2}\right)$. The results show that, with increasing temperature, the amount of short-circuit surface current density drops to a much lesser extent. In general, as the temperature increases from 200 to $400 \mathrm{~K}$, the short-circuit current decreases imperceptibly. This trend of imperceptible reduction of short-circuit current with increasing temperature is consistent with the results of the previous two works [16, 27-29]. In [28], cadmium telluride solar cells with different dorsal connections have been studied. In their work, with increasing temperature from 300 to $380 \mathrm{~K}$, the short-circuit current has decreased imperceptibly from $24.184575\left(\mathrm{~mA} / \mathrm{cm}^{2}\right)$ to $24.169443\left(\mathrm{~mA} / \mathrm{cm}^{2}\right)$. In [27], cadmium telluride solar cells have been studied. In their work, as the temperature increased from 200 to $400 \mathrm{~K}$, the short-circuit current decreased imperceptibly from 23.900 $\left(\mathrm{mA} / \mathrm{cm}^{2}\right)$ to $23.882\left(\mathrm{~mA} / \mathrm{cm}^{2}\right)$. 


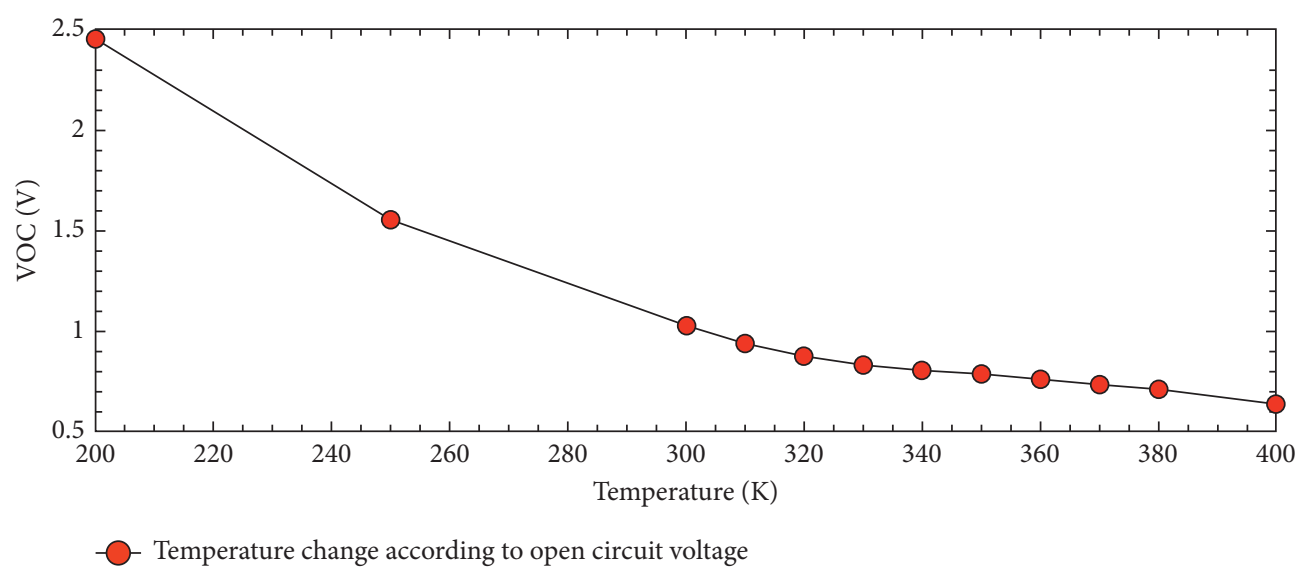

Figure 3: Open-circuit voltage changes with temperature at a thickness of $2000 \mathrm{~nm}$ CdTe.

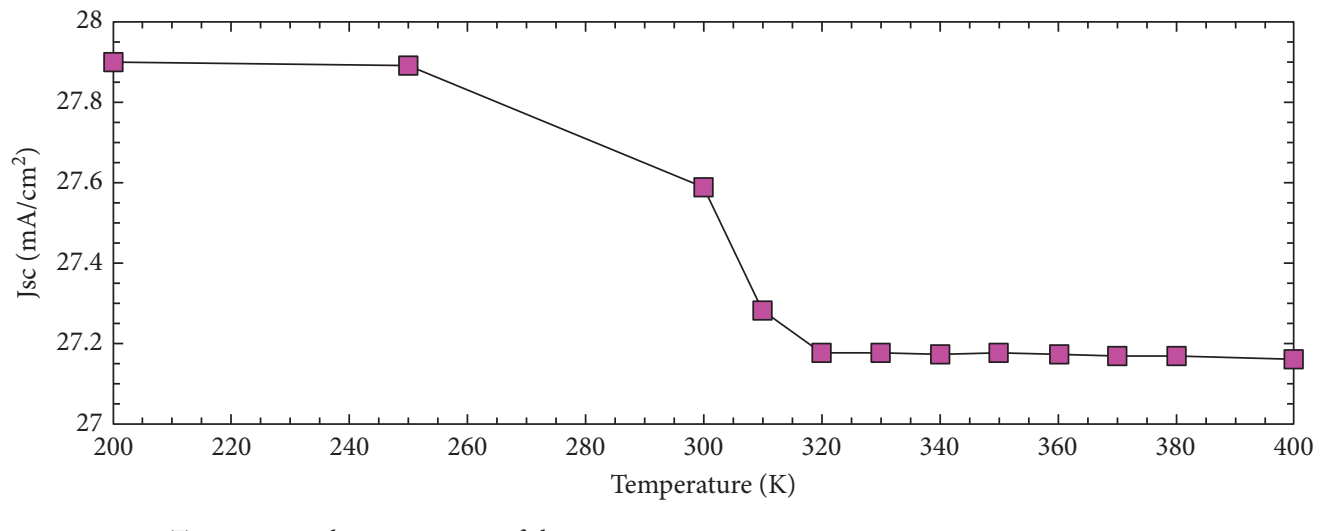

Temperature change in terms of short circuit current

Figure 4: The short-circuit surface current density changes in the temperature range $200-400 \mathrm{~K}$ at a thickness of $2000 \mathrm{~nm}$ CdTe.

Figure 5 shows the filling factor versus the temperature variation from 200 to 400 Kelvin when the thickness of cadmium telluride is $2000 \mathrm{~nm}$. The filling factor is in the range of 0.4707 to 0.8938 , so that, at a temperature of about 200 Kelvin, the filling factor is equal to 0.4707 , and at room temperature of 300 Kelvin, the filling factor reaches 0.8583 , which is consistent with the previous works. Unlike opencircuit voltage and short-circuit current, which decreases with increasing temperature, the results show that the filling factor increases first and then decreases with increasing temperature. So that, from 200 to 330 Kelvin, the amount of filling factor increases and in 330 Kelvin reaches the maximum value and from 340 to 400 Kelvin the number of filling factors slightly decreases. In [28], cadmium telluride solar cells with different dorsal connections have been studied. In their work, with increasing temperature from 300 to $380 \mathrm{~K}$, the filling factor first increases with increasing temperature and at $330 \mathrm{~K}$, it reaches the maximum value and then decreases. In [27], cadmium telluride solar cells have been studied. In their work, with increasing the temperature from 200 to $400 \mathrm{~K}$, the filling factor is first increased and at $350 \mathrm{~K}$, it reaches the maximum value and then decreases. The trend of changes in the filling factor in $[27,28]$ confirms the correctness of our work.
Figure 6 shows the efficiency versus temperature changes from 200 to $400 \mathrm{~K}$ when the thickness of cadmium telluride is $2000 \mathrm{~nm}$. The efficiency of the solar cell is in the range of $32.29 \%$ to $15.53 \%$ so that at a temperature of about 200 Kelvin, the efficiency is equal to $32.29 \%$, and at room temperature of 300 Kelvin, the efficiency reaches $24.39 \%$, which is consistent with previous work [4]. As with opencircuit voltage and short-circuit current, which decreases with increasing temperature, the results show that the efficiency decreases with increasing temperature. At a temperature of $400 \mathrm{~K}$, the minimum efficiency is $15.53 \%$. As the temperature increases, the efficiency of the cell decreases linearly which indicates the degree of stability of the cell at high temperatures. In all the simulation steps in this work, the mobility and bandgap are independent of temperature [27]. In [27], with increasing temperature from 200 to $400 \mathrm{~K}$, the efficiency decreases linearly from $18.44 \%$ to $10.48 \%$. In [16] where $\mathrm{CdTe} / \mathrm{CdS}$ solar cells have been studied, the efficiency decreases linearly with increasing temperature. In addition, in [28], with increasing temperature from 300 to $380 \mathrm{~K}$, the efficiency decreases linearly from $16.04 \%$ to $11.62 \%$. In $[16,27,28]$ with increasing temperature, the efficiency decreases linearly which confirms the results of our work. 


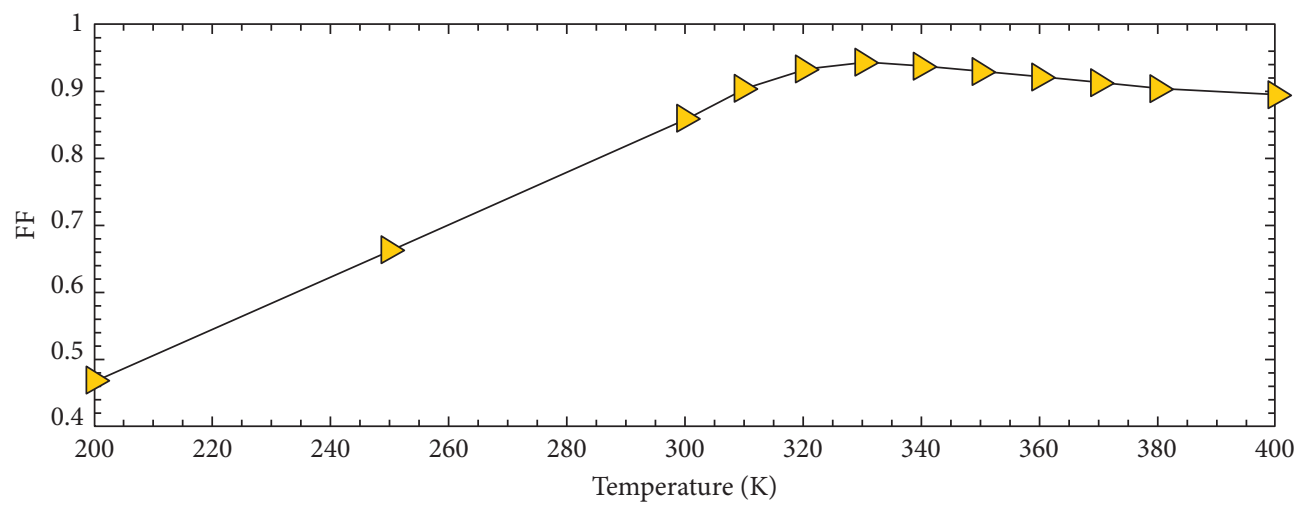

$\rightarrow$ Temperature change in terms of Filling coefficient

Figure 5: Filling factor versus temperature at a thickness of $2000 \mathrm{~nm}$ from CdTe.

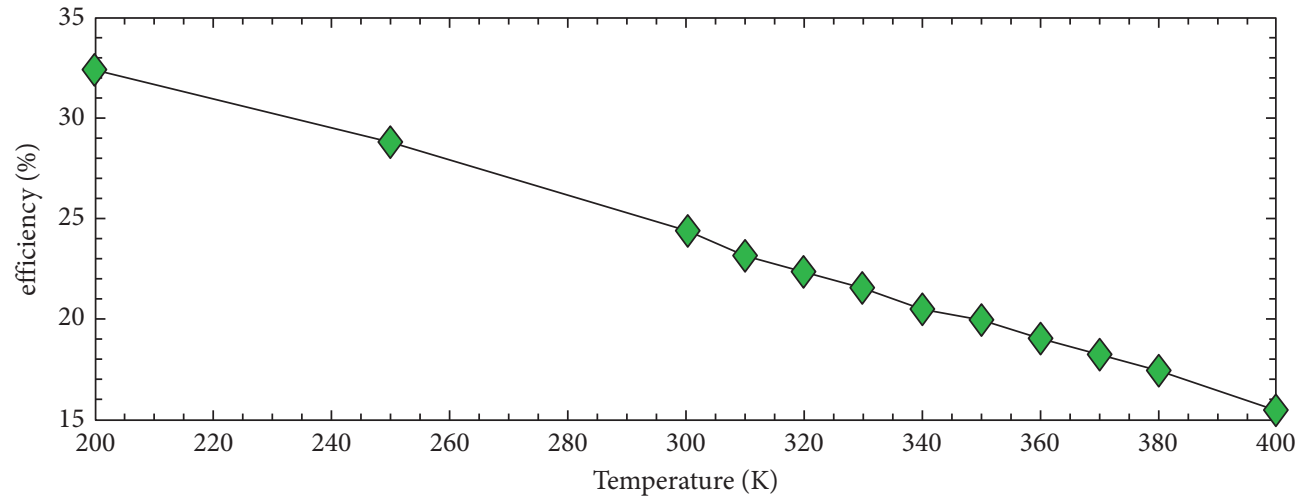

Temperature change in terms of efficiency

Figure 6: Efficiency versus temperature changes at a thickness of $2000 \mathrm{~nm}$ CdTe.

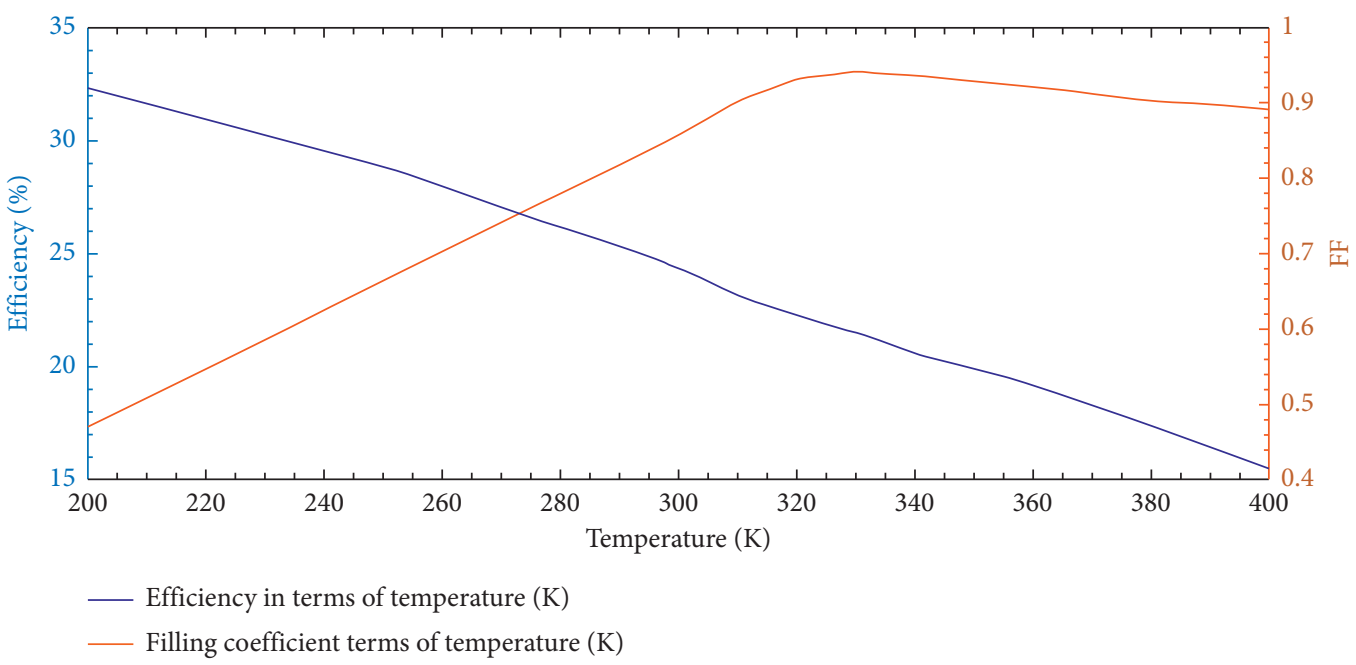

Figure 7: Filling factor and efficiency in terms of temperature changes at a thickness of $2000 \mathrm{~nm}$ CdTe.

For better observation and comparison, the variation of filling factor and efficiency in terms of temperature changes are shown simultaneously in Figure 7. Solar cell performance decreases with increasing temperature, indicating an increase in internal carrier recombination rates or dark current, caused by increased carrier concentration [27].

In addition, the efficiency measurement of a solar cell is given as 


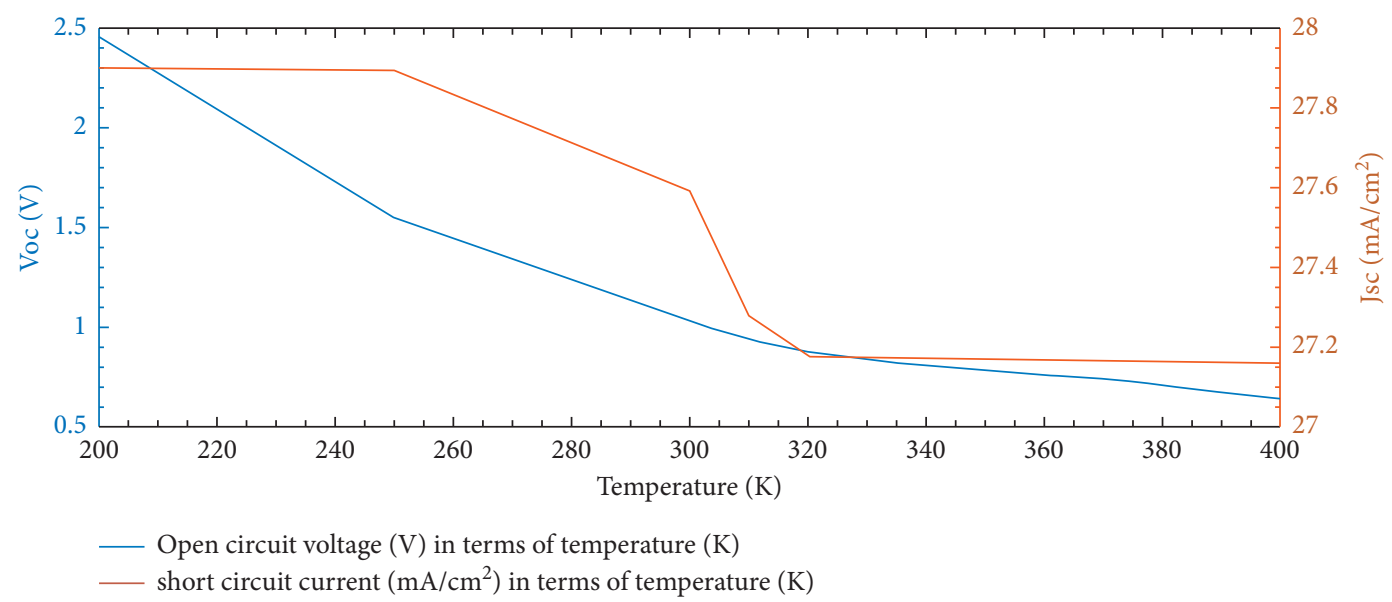

FIgURE 8: Short-circuit current and open-circuit voltage in terms of temperature changes at a thickness of $2000 \mathrm{~nm}$ CdTe.

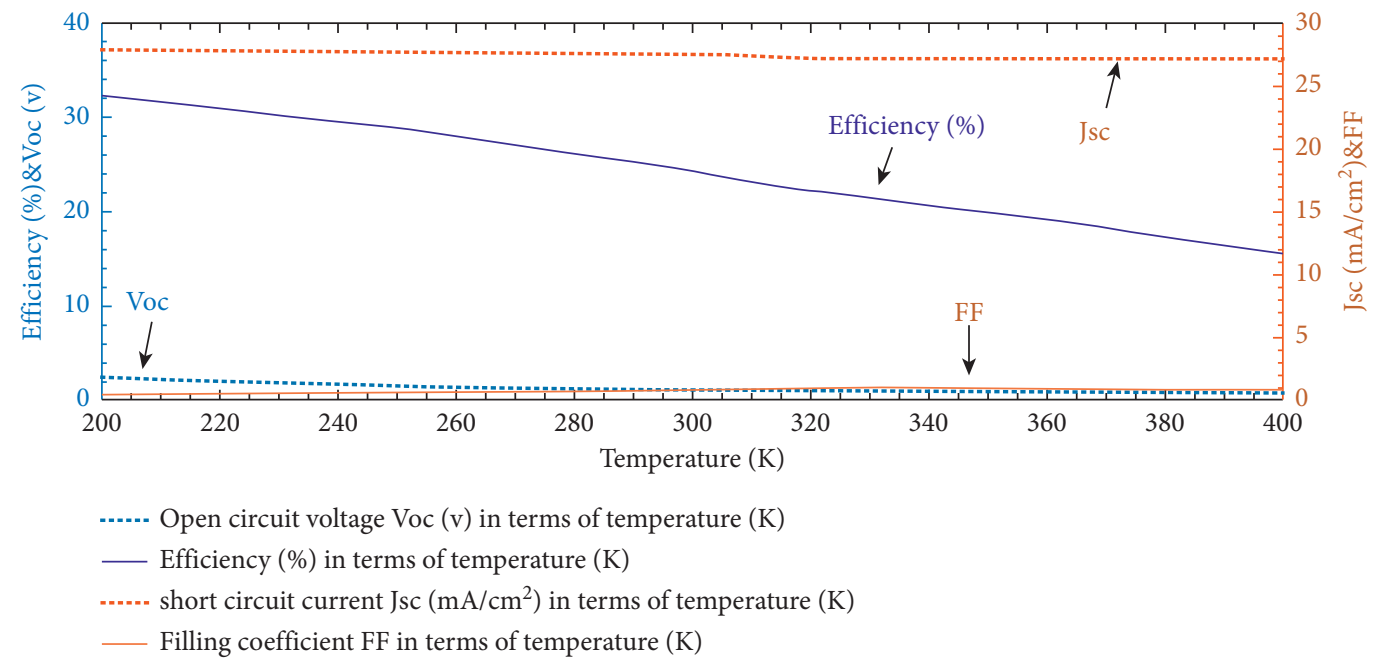

FIGURE 9: Open-circuit voltage (blue dashed line), short-circuit current (red dashed line), filling factor (red line), and efficiency (blue line) versus temperature.

$$
\eta=\frac{V_{\mathrm{oc}} J_{\mathrm{sc}} \mathrm{FF}}{P_{\mathrm{in}}}
$$

where $P_{\text {in }}$ is the solar irradiance on Earth under the AM1.5 Global spectrum [29].

The short-circuit current and the open-circuit voltage are the maximum current and voltage in a solar cell, respectively. However, power output is zero at both of these values. The fill factor, FF, is a parameter that, in conjunction with Voc and Jsc, determines the maximum power from a solar cell. The FF is defined as the ratio of the maximum power from the solar cell to the product of Voc and Jsc.

Figure 8 shows the open-circuit voltage together with the short-circuit current versus temperature range $200-400 \mathrm{~K}$. Both open-circuit voltage and short-circuit current decrease with increasing temperature.

A similar trend has been observed in earlier studies [28] for $\mathrm{FTO} / \mathrm{SnO}_{2} / \mathrm{CdS} / \mathrm{CdTe} / \mathrm{Pt}$ which has a similar structure to ours except with platin back contact.
Figure 9 shows the open-circuit voltage and efficiency (vertical axes on the left) and the filling factor and shortcircuit current (vertical axes on the right) in terms of temperature as mentioned before, the trend of open-circuit voltage changes, short-circuit current, filling factor and efficiency in our work corresponds to $[27,28]$ which prove the correctness of our work.

\section{Conclusion}

Although the parameter temperature has a key role in solar cells, it is not much attended by many researchers. In this paper, we consider a multilayer solar cell consisting of FTO/ $\mathrm{SnO}_{2} / \mathrm{CdS} / \mathrm{CdTe} / \mathrm{Cu}_{2} \mathrm{O}$ layers. The structure was optimized in previous studies at room temperature regardless of temperature changes. Till now temperature changes in this structure had not been simulated and studied. The temperature-dependent performance parameters, such as shortcircuit current density (Jsc), open-circuit voltage (Voc), 
filling factor (FF), and conversion efficiency $(\eta)$ of CdTebased solar cell have been analyzed with the temperature change ranges from 200 to $400 \mathrm{~K}$ indicating the electrical properties such as Jsc and Voc are very important in solar cell performance. It was observed that temperature directly affects the electrical properties of CdTe solar cells. An increase in temperature due to solar illumination directly affects in poor performance of properties such as Jsc and Voc.

The novelty of our work is its ability in attaining confirmed accurate results and little effort in computational simulation executed. In other words, the main novelty of this article is that while it is simple, it has high accuracy. As the cell temperature increased from 200 to $400 \mathrm{~K}$, the efficiency of the solar cells decreased from $32.29 \%$ to $15.53 \%$. The filling factor also increased with increasing temperature from 200 to 400 Kelvin and at 330 Kelvin reached its maximum value of 0.9419 and then decreased. Open-circuit voltage and short-circuit current also decreased with increasing temperature from 200 to 400 Kelvin. Performance analysis of the numerical simulation using MATLAB shows that the theoretical efficiency of the CdTe-based solar cell has been improved to $32.29 \%$ with a fill factor of 0.4707 , a shortcircuit current of $27.9\left(\mathrm{~mA} / \mathrm{cm}^{2}\right)$, and an open-circuit voltage of 2.45 volts.

\section{Data Availability}

Data are available on request.

\section{Conflicts of Interest}

The authors declare that they have no conflicts of interest.

\section{References}

[1] M. Hashemi, M. Minbashi, S. M. B. Ghorashi, and A. Ghobadi, "A modeling study on utilizing low temperature sprayed In2S3 as the buffer layer of CuBaSn (S, Se) solar cells," Scientific Reports, vol. 11, no. 1, pp. 1-11, 2021.

[2] O. D. Iakobson, O. L. Gribkova, A. R. Tameev, and J. M. Nunzi, "A common optical approach to thickness optimization in polymer and perovskite solar cells," Scientific Reports, vol. 11, no. 1, pp. 5005-5006, 2021.

[3] W. K. Metzger, S. Grover, D. Lu et al., "Exceeding 20\% efficiency with in situ group V doping in polycrystalline CdTe solar cells," Nature Energy, vol. 4, no. 10, pp. 837-845, 2019.

[4] I. E. Tinedert, A. Saadoune, I. Bouchama, and M. A. Saeed, "Numerical modelling and optimization of CdS/CdTe solar cell with incorporation of Cu2O HT-EBL layer," Optical Materials, vol. 106, Article ID 109970, 2020.

[5] A. Kuddus, A. B. M. Ismail, and J. Hossain, "Design of a highly efficient CdTe-based dual-heterojunction solar cell with $44 \%$ predicted efficiency," Solar Energy, vol. 221, pp. 488-501, 2021.

[6] D. K. Shah, D. Kc, M. Muddassir, M. S. Akhtar, C. Y. Kim, and O.-B. Yang, "A simulation approach for investigating the performances of cadmium telluride solar cells using doping concentrations, carrier lifetimes, thickness of layers, and band gaps," Solar Energy, vol. 216, pp. 259-265, 2021.

[7] P. Hatton, M. J. Watts, A. Abbas, J. M. Walls, R. Smith, and P. Goddard, "Chlorine activated stacking fault removal mechanism in thin film CdTe solar cells: the missing piece," Nature Communications, vol. 12, no. 1, pp. 4938-4939, 2021.

[8] T. Ablekim, J. N. Duenow, C. L. Perkins et al., "Exceeding 200-ns lifetimes in polycrystalline CdTe solar cells," Solar RRL, 2021.

[9] G. V. Kaliyannan, R. Gunasekaran, S. Sivaraj, S. Jaganathan, and R. Rathanasamy, "Thin-film solar cells," Fundamentals of Solar Cell Design, pp. 103-115, 2021.

[10] T. Walker, M. E. Stuckelberger, T. Nietzold et al., "The nanoscale distribution of copper and its influence on charge collection in CdTe solar cells," Nano Energy, vol. 91, Article ID 106595, 2021.

[11] F. Deng, X. Sun, X. Lv et al., "All room-temperature processing efficient planar carbon-based perovskite solar cells," Journal of Power Sources, vol. 489, Article ID 229345, 2021.

[12] D. Ouyang, J. Zheng, Z. Huang, L. Zhu, and W. C. H. Choy, "An efficacious multifunction codoping strategy on a roomtemperature solution-processed hole transport layer for realizing high-performance perovskite solar cells," Journal of Materials Chemistry, vol. 9, no. 1, pp. 371-379, 2021.

[13] D. Cao, A. Wang, X. Yu et al., "Room-temperature preparation of $\mathrm{TiO}_{2}$ /graphene composite photoanodes for efficient dye-sensitized solar cells," Journal of Colloid and Interface Science, vol. 586, pp. 326-334, 2021.

[14] W. Huang, R. Zhang, X. Xia et al., "Room temperature processed double electron transport layers for efficient perovskite solar cells," Nanomaterials, vol. 11, no. 2, p. 329, 2021.

[15] H.-C. Lin, L.-Y. Chen, and T.-H. Lin, "Improving hysteresis of room-temperature air-quenching MAPbI3-xClx solar cells by using mixed-lead halide precursor," Materials Chemistry and Physics, vol. 259, Article ID 124032, 2021.

[16] H. Heriche, Z. Rouabah, and N. Bouarissa, "New ultra thin CIGS structure solar cells using SCAPS simulation program," International Journal of Hydrogen Energy, vol. 42, no. 15, pp. 9524-9532, 2017.

[17] Y. Liu, Y. Sun, and A. Rockett, "A new simulation software of solar cells-wxAMPS," Solar Energy Materials and Solar Cells, vol. 98, pp. 124-128, 2012.

[18] S. Michael and A. Bates, "The design and optimization of advanced multijunction solar cells using the Silvaco ATLAS software package," Solar Energy Materials and Solar Cells, vol. 87, no. 1-4, pp. 785-794, 2005.

[19] S. Michael, A. D. Bates, and M. S. Green, "Silvaco ATLAS as a solar cell modeling tool," in Proceedings of the Conference Record of the Thirty-First IEEE Photovoltaic Specialists Conference, pp. 719-721, IEEE, Lake Buena Vista, FL, USA, January 2005.

[20] M. Mostefaoui, H. Mazari, S. Khelifi, A. Bouraiou, and R. Dabou, "Simulation of high efficiency CIGS solar cells with SCAPS-1D software," Energy Procedia, vol. 74, pp. 736-744, 2015.

[21] A. K. Mishra and R. K. Shukla, "Electrical and optical simulation of typical perovskite solar cell by GPVDM software," Materials Today Proceedings, 2020.

[22] J. Qu, L. Zhang, H. Wang, X. Song, Y. Zhang, and H. Yan, "Simulation of double buffer layer on CIGS solar cell with SCAPS software," Optical and Quantum Electronics, vol. 51, no. 12, pp. 1-14, 2019.

[23] A. Fell, J. Schön, M. C. Schubert, and S. W. Glunz, "The concept of skins for silicon solar cell modeling," Solar Energy Materials and Solar Cells, vol. 173, pp. 128-133, 2017.

[24] M. Elbar and S. Tobbeche, "Numerical simulation of CGS/ CIGS single and tandem thin-film solar cells using the SilvacoAtlas software," Energy Procedia, vol. 74, pp. 1220-1227, 2015.

[25] P. Khaledi and Y. Abedini, "Simulation And Investigation of the Optical Properties of cds/cdte solar cells," in Proceedings of 
the International Conference on Optoelectronic, Applied Optics and Microelectronics (OAM-2019), Ardabil, Iran, August 2019.

[26] I. E. Tinedert, F. Pezzimenti, M. L. Megherbi, and A. Saadoune, "Design and simulation of a high efficiency CdS/ CdTe solar cell," Optik, vol. 208, Article ID 164112, 2020.

[27] M. M. Isa, I. Mustapha, and A. A. Yahaya, "Numerical modelling of the effect of temperature and thickness on the electrical properties of polycrystalline semi-conductor solar cells [CdTe and $\mathrm{Cu}$ (in, Ga) Se2 (CIGS)] using one dimensional device simulation," IOP Conference Series: Earth And Environmental Science, vol. 730, no. No. 1, Article ID 012027, 2021.

[28] V. Shukla and G. Panda, "The performance study of CdTe/ CdS/SnO2 solar cell," Materials Today Proceedings, vol. 26, pp. 487-491, 2020.

[29] M. A. Green, Solar Cells: Operating Principles, Technology, and System Applications/Martin A. Green, Prentice-Hall, Englewood Cliffs, NJ, USA, c1982. 